\title{
Assessing the economic impacts of drought from the perspective of profit loss rate: a case study of the sugar industry in China
}

\author{
Y. Wang ${ }^{1,2}$, L. Lin $^{1,2}$, and H. Chen ${ }^{1,2}$ \\ ${ }^{1}$ Key Laboratory of Environmental Change and Natural Disaster of MOE, Beijing Normal University, No. 19, \\ XinJieKouWai St., HaiDian District, 100875 Beijing, China \\ ${ }^{2}$ Academy of Disaster Reduction and Emergency Management, Beijing Normal University, No. 19, XinJieKouWai St., \\ HaiDian District, 100875 Beijing, China \\ Correspondence to: Y. Wang (wy@bnu.edu.cn)
}

Received: 20 December 2014 - Published in Nat. Hazards Earth Syst. Sci. Discuss.: 23 February 2015

Revised: 1 June 2015 - Accepted: 16 June 2015 - Published: 23 July 2015

\begin{abstract}
Natural disasters have enormous impacts on human society, especially on the development of the economy. To support decision-making in mitigation and adaption to natural disasters, assessment of economic impacts is fundamental and of great significance. Based on a review of the literature on economic impact evaluation, this paper proposes a new assessment model of the economic impacts of droughts by using the sugar industry in China as a case study, which focuses on the generation and transfer of economic impacts along a simple value chain involving only sugarcane growers and a sugar-producing company. A perspective of profit loss rate is applied to scale economic impact. By using "with and without" analysis, profit loss is defined as the difference in profits between disaster-hit and disaster-free scenarios. To calculate profit, analysis of a time series of sugar price is applied. With the support of a linear regression model, an endogenous trend in sugar price is identified and the time series of sugar price "without" disaster is obtained, using an autoregressive error model to separate impact of disasters from the internal trend in sugar price. Unlike the settings in other assessment models, representative sugar prices, which represent value level in disaster-free conditions and disaster-hit conditions, are integrated from a long time series that covers the whole period of drought. As a result, it is found that in a rigid farming contract, sugarcane growers suffer far more than the sugar company when impacted by severe drought, which may promote reflections among various economic bodies on economic equality related to the occurrence of natural disasters. Further, sensitivity analysis of the model built reveals that sugarcane purchase price has
\end{abstract}

a significant influence on profit loss rate, which implies that setting a proper sugarcane purchase price would be an effective way of realizing economic equality in future practice of contract farming.

\section{Introduction}

Given the current background of climate change, scientists worldwide are increasingly concerned about the impact of frequent natural disasters (West and Lenze, 1994; Pelling and Uitto, 2001; Lindell and Prater, 2003; Toya and Skidmore, 2007). The occurrence of large-scale natural disasters causes severe fatalities and heavy economic impacts (Kahn, 2005; Yuan, 2008; Hallegatte, 2008). To improve the understanding of the economic consequences of natural disasters and to contribute to policy decisions on disaster mitigation and prevention, evaluations of the economic impacts of natural disasters are undoubtedly fundamental.

The economic impacts of natural disasters can be assessed from many perspectives, using different terms such as "damage", "cost" and "loss" that portray the influence of disasters on the economy (Logar and van den Bergh, 2013; Brémond et al., 2013; Meyer et al., 2013). Monetary benefits that are diminished by the occurrence of disasters are widely applied in the assessment, such as the term "income loss" that is computed by commodity price multiplied by the amount of goods destroyed in disasters. For example, when assessing the economic impact of extreme flood events in central Vietnam on agricultural production, Chau et al. (2015) use the historical 
data from floods that happened in 2004, 2009 and 2007 to interpret floods with return period of 10 years, 20 years and 100 years, respectively. With the support of these historical data, susceptibility rates and damage functions of four main crop types are obtained. The agricultural data from 2010 are provided as "normal" conditions without extreme floods. Then, applying the susceptibility rates and damage functions mentioned above, the income losses, which are the revenues calculated from the amounts of estimated crop damage multiplied by 2010 crop prices, will be determined for different scenarios of floods. Similarly, Gil et al. (2013) and Diersen and Taylor (2003) also make an assessment of economic impacts based on the concept of income loss.

On the other hand, many studies consider cost in addition to income, in their assessment of economic impacts of disasters, and therefore they mainly focus on the term "profit loss" induced by disasters. In an economic assessment of drought effects on grassland systems in Switzerland, Finger et al. (2013) apply a method, based on drought experiments by controlling water conditions in fields, which is able to obtain grassland yields in normal and drought conditions. With the support of related cost and benefit information, profit margins (profit per hectare) of both normal and drought scenarios are generated, and profit loss can be calculated from the difference in the profit margin of these two scenarios. Similarly, Booker and Colby (1995) and MartinOrtega et al. (2012) also propose an assessment of economic impact from the perspective of profit loss or benefit loss.

Moreover, the term "percentage loss", which measures the severity of economic impacts by calculating the ratio of loss to total quantity in non-disaster conditions, is also frequently used in assessing economic impacts. For example, Pauw et al. (2011) develop a model combining an hydrometeorological method and CGE (computable general equilibrium) analysis to evaluate the economic impact of extreme weather events in Malawi. With the application of an hydrometeorological method, drought loss exceedance curves are generated that reveal the relationship between percent of crop loss and drought severity. Then, by analysing the CGE, the impacts on the GDP (gross domestic product) of several sectors, presented as a percentage loss, are obtained for different levels of droughts to make it easier to compare economic impacts in different sectors. Not only CGE models (Horridge et al., 2005) but also IO (Input-Output) models (Jenkins, 2013; Xie et al., 2012) can fulfil such analysis.

After reviewing those perspectives used in recent studies, by using the terms "income loss" and "profit loss", absolute value of economic impacts can be assessed, which will be useful to stakeholders who are concerned with related industries. However, with limited background information, it is hard for disaster researchers who know little about such fields to compare loss for different individuals. On the other hand, the term "percentage loss" is mainly used in macroeconomic research; it helps to compare disaster impacts by using the relative value of disaster loss, but at the same time, it needs more development if is to be applied on an individual level. This paper argues that some new term combining all advantages of the above terms should be developed to properly illustrate comparable economic impacts based on net value loss. In this paper, the term "profit loss rate" is proposed, which is the ratio of impact on profit (i.e. the difference of profit in disaster-free and disaster-hit conditions) to profit in non-disaster conditions. This serves as a new perspective to scale and represent the economic impacts of disasters.

As an important factor in all studies that include the assessment of economic impacts, an endogenous trend in price will attract much attention. When observing long time series of commodity price, it is found that for some certain commodities, price follows quite a regular cycle for many years (Cashin et al., 2002; Cuddington, 1992). That is, the change in the price after the occurrence of disasters cannot be fully attributed to the disaster event itself, but it is also partly due to the dynamics of price. To have a good understanding of the impact of disasters, the underlying trend of price shall be removed. However, few papers actually take the time trend of agrifood price into consideration. In literature considering evolution of price, Gil et al. (2013) include price index and trend of agricultural production in building a model for assessing drought impacts. The influences of price and time trend on production value are considered. When the price trend is not fully investigated before estimating its impact on price, it remains unclear whether the difference in price between disaster-hit and disaster-free conditions is driven by natural disasters. Thus, it would bring great uncertainty to the final result and consequently reduce the precision of the result.

Furthermore, in some slow-onset disasters such as drought, the prices of commodities affected by disasters keep changing, and when different amounts of commodities are sold for different prices, setting proper representative prices, which can illustrate commodity value levels in different scenarios, becomes very important because it greatly influences the production value and final results. However, among the present studies, variations in price or price dynamics during disasters is seldom addressed, and many papers still hold a static view on choosing representative price. For example, a price at some point before the occurrence of a disaster is generally chosen to represent the price level in a disasterfree scenario (Holt-Giménez, 2002; Chau et al., 2015; Finger et al., 2013). With the development of a disaster event, its impact continues to change, and the prices of marketoriented commodities must also always change. Without paying attention to the changing series of price, it is difficult to obtain a good representative price. For example, without a good representative price-setting method, the pre-disaster price, which is usually regarded as the price in disaster-free conditions, will not be able to represent the value level in non-disaster conditions but only in pre-disaster conditions, leading to a failure in the precision of the assessment results. Therefore, a dynamic view shall be applied, and setting rep- 
resentative prices that can illustrate commodity value levels in different scenarios will be better considered when assessing economic impacts on highly market-oriented commodities.

To address these gaps mentioned above, this paper presents a case study of the sugarcane-growing region in Yunnan province, China. This work investigates the local model of contract farming involving sugarcane growers and a sugar-producing company. A trend in sugar price is identified from a linear regression model. By using an autoregressive error model, a time series of sugar price for disasterfree scenarios is projected with the support of pre-disaster sugar price data, and then representative sugar prices for both disaster-hit and disaster-free conditions are calculated by integrating the variation in price series; hence, revenues are obtained. Using the revenue and cost of growers and the company, both of their profit loss rates are generated. The results reveal economic inequality in the process of disaster economic loss allocation in contract agriculture. Sensitivity analysis of profit loss rates shows that setting a proper sugarcane purchase price would be a good solution. This study provides a framework describing economic impacts on the agrifood value chain using the "with and without" analysis (Guimaraes et al., 1993), in the hope of providing a reference for the better consideration of economic equality during adaption to natural disasters.

This paper is organized into five sections. In Sect. 2, background information about research regions and the 2009/2010 drought is provided; specifically, the reason for selecting such a case study is emphasized. Section 3 explains the method of evaluating the impact of drought on sugar price, which includes identification of price trends, estimation of sugar prices in non-disaster conditions and the calculation of representative prices for both scenarios. Using outcomes from Sect. 3, Sect. 4 makes an assessment of the economic impact of a drought from the perspective of profit loss rate and sensitivity analysis is also introduced. Further discussion is presented in Sect. 5. Finally, Sect. 6 draws a conclusion for the whole paper.

\section{Background}

\subsection{Study region}

Yunnan province is an important sugar production area in China, with annual sugar production comprising approximately $20 \%$ of the total domestic production. Yuanjiang county is one of the most suitable sugarcane-planting regions. Sugarcane-squeezing and sugar processing is the county's traditional pillar industry, boasting an output value representing $14.70 \%$ of the county's GDP. Yuanjiang is a minority autonomous county of the Hani, Yi and Dai ethnic minorities. The county population is approximately 201800 , of which $86.38 \%$ is engaged in farming.
Jinke Group Sugar Co. Ltd. (hereafter also referred to as the "sugar company") is a leading company in the sugar industry of Yuanjiang. The Jinke Group has four machineprocessing sugar refineries and four modern production lines, in addition to a daily processing capacity of 8500 tons of sugarcane. The Group's sugarcane raw material production is based in Yuanjiang county, and it signs contracts for sugarcane purchase with local growers at the beginning of each planting season. The contracts contain fixed purchase prices, planting technical advice, planting areas, purchasing methods and other information. After the harvest, the company must buy growers' sugarcane at the price prescribed in the contract, without any modification.

The sugarcane purchase price $\left(P_{\text {order }}\right)$ is the price stated in the farming contract for which the sugar company will buy sugarcane from growers after harvesting. It is the paramount part of the contract, for these prices affect eventual profits on both sides. With a fixed purchase price, growers who are riskaverse may feel safer about future income and in addition, the sugar company will be able to estimate its finance in squeezing season more reliably (Prowse, 2012). Mostly, such prices are decided by the local government which, to some extent, comes from the sugar price in past years and the predictions of future sugar markets by officials' experiences.

To facilitate agreement on both sides, the Yuanjiang county government established the Yuanjiang county sugar office to open a channel of communication between the company and growers, to balance and coordinate the relationship between production and marketing, to guide growers and the company in signing and performing according to the contract and to advise growers on proper field operations to meet contract requirements.

About $80 \%$ of sugarcane growers have contracts with Jinke because the Group is succeeding financially, and it can provide better help with planting technology when growers need it. Those $20 \%$ growers who do not have contracts with Jinke will find buyers by themselves, for example, by selling to small companies or transporting their products to sell in other neighbouring counties. The order performance rate is the proportion of growers who fulfil the farming contracts after harvesting compared to those growers who sign farming contracts when the planting season begins. Such a rate that demonstrates the successfulness of local contract farming is always about $80 \%$ because of relatively fair purchase prices from the Jinke Group, the largest sugar company in the county and surrounding areas, and because of immediate supervision from government departments. Thus, an independent and complete chain of the sugar industry has emerged between sugarcane growers and the sugar company in Yuanjiang county. Figure 1 shows the structure of such a chain including growers and the sugar company. The chain in this model is linked in a relatively simple manner, in which growers and the sugar company are the main parts that this paper concerns. 


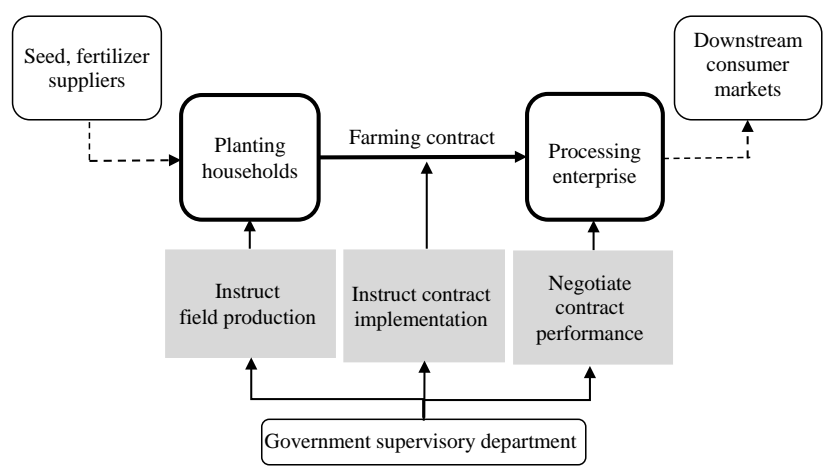

Figure 1. Basic structure of the sugar industry of contract farming in Yuanjiang.

\subsection{Study case}

For sugarcane, long-lasting drought can cause severe yield reduction and thus an enormous decrease in the production of sugar. Because the sugar market in China is always in slightly short supply, once sugar production decreases, there is great difficulty in providing enough sugar supply and the sugar price rises as a result. In Yuanjiang county, from 1995 to 2010 , rising of sugar price often appears with droughts, especially in those years with severe droughts, as shown in Fig. 2. From Fig. 2, the index of precipitation anomaly percentage shows that the precipitation of Yuanjiang in 2000, 2006 and 2010 is quite low compared to average conditions; hence, the sugar prices of those months with severe droughts continue in a rising trend. Among these periods, the 2009/2010 drought was of great severity and its impact on sugar production of Yunnan was quite huge.

The 2009/2010 drought, which lasted from October 2009 to February 2010 in southwestern China, was the driest event in the past 50 years, with minimum rainfall and maximum non-rain days (Yang et al., 2012). The Yunnan province suffered the most loss among the provinces affected. The volumes of most rivers were about 30 to $80 \%$ less than in average conditions and some rivers even dried up. As declared by the Yunnan province information office, this drought caused water shortages for 8.2 million people and 3.1 million hectares of crops (Lu et al., 2011). During this catastrophic drought, the sugar industry of Yuanjiang county suffered greatly. In the 2009/2010 season, the amount of sugarcane production was just 439600 tons, a decline of 215300 tons or $32.88 \%$ from the officially estimated production in a non-disaster scenario (Bureau of Statistics of Yuanjiang autonomous county of Hani, Yi and Dai, 2010, 2011).

The 2009/2010 drought was not only selected as a case study because of its tremendous impact on sugar production, but also because during this period, potential factors that may influence sugar price, excluding the occurrence of drought, do not have significant impacts on sugar price; thus to con- nect drought severity with a rise in sugar price is reasonable and practical.

China is a high sugar-consuming country for its large population and sugar is always in slightly short supply. Therefore, sugar is rarely exported from China. For the aspect of importation, the amount of sugar imported is always under strict control because China runs a TRQ (tariffrate quota) system for importing many agricultural products including sugar. In 2009, the quota of sugar imported was 1.945 million tons (Ministry of Commerce, P. R. China, 2008) and the actual amount of sugar imported was only 1.064 million tons (Yunnan Sugar Network, 2010). In contrast, China produced about 11 million tons of sugar domestically in the 2009/2010 season (Xinhua Net, 2010). Therefore, as imported sugar accounts for fewer than $9 \%$ of sugar products in China, the importation of sugar can hardly have a great influence on domestic sugar price.

In the sugar market of China, state sugar reserves play a special role. The central government buys sugar when market price is low and sells sugar when the price is high; this intends to stabilize the sugar price. Between April 2009 and April 2010, the central government had four auctions of state sugar reserves (Foreign Agricultural Service, USDA, 2010). However, the effect of stabilizing sugar price is not that significant. Every time state sugar reserves are released, the trend of sugar price is not influenced. Unexpectedly, it seems that on the contrary, the release of state sugar reserves encourages the rise of sugar price because the action of release is a signal that the sugar market is in short supply.

The time range used in this paper is from April 2009 to September 2010, which is mainly decided by the time of sugarcane production and sugar production. The growing season of sugarcane in Yunnan is from April to October during which sugarcane growers complete all aspects of sugarcane planting, like sowing, planting, cultivating and harvesting. The production season of the sugar company is from October to September the following year, during which the sugar company completes all aspects of sugar production, like purchasing raw materials, sugar squeezing, processing and marketing. By using the time range covering the whole period from sugarcane planting to sugar sales, existing economic data of the sugar industry can be applied in this research and hence actual economic states of both growers and the company can be efficiently captured; this will help to assess accurate disaster impacts.

\section{Impact of drought on sugar price}

As mentioned above, when observing long time series of some commodity prices, it is found that for some types of commodities, their prices follow quite a regular trend or cycle for many years. Such phenomena also appear in the time series of sugar price in China. The sugar price in the spot market was developing in an ascending trend when the 


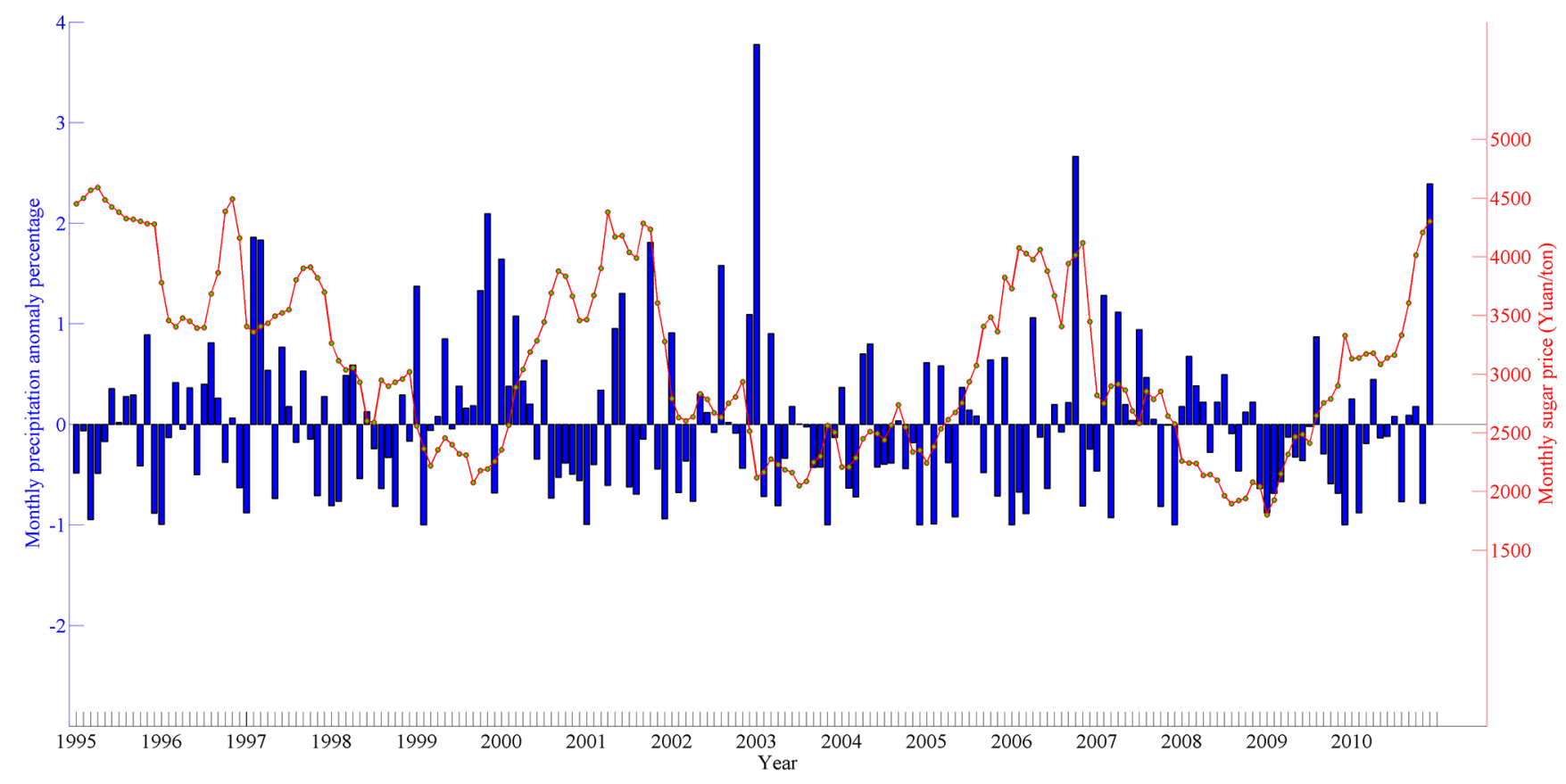

Figure 2. Comparison of precipitation anomalies and sugar price from 1995 to 2010 in Yuanjiang.

2009/2010 drought occurred. Therefore, it is quite necessary to take this trend into consideration for estimation of sugar prices in non-disaster conditions. After obtaining the time series of sugar price "without" disaster, the impact of the drought can be calculated.

To estimate the impact of drought on sugar prices, a time series analysis was applied to estimate the sugar price for a disaster-free scenario. By using linear regression analysis of sugar price and time over a long time period, a linear trend is found in the variation of sugar price. Then, an autoregressive error model is applied to estimate the "without-disaster" sugar price with the support of pre-disaster series. Hence, the comparison of real price in a disaster year and the estimated price in a disaster-free scenario reveals the impact of drought on sugar price.

When setting a proper time series, the daily sugar price in Kunming spot market was used to represent the spot sugar price of Yuanjiang county during the great drought. The data were extracted from the Yunnan Sugar Network (2014), a famous sugar industry website in China providing information on the national sugar industry and daily prices in sugar in different spot markets.

\subsection{Trends of sugar price over a long period}

Comparing the monthly average sugar price of Kunming from December 1999 to December 2013, which has been fixed based on December $2006^{1}$ using month-to-month CPI

\footnotetext{
${ }^{1}$ The reason why December 2006 is chosen as the beginning for CPI deflation has two aspects. On the one hand, the month-to-
}

(consumer price index) data (National Bureau of Statistics of the People's Republic of China, 2014) to remove the influence of recent rapid development of CPI in China on sugar price, implies three cycles of fluctuation in sugar price during the last 14 years. According to the increasing or decreasing trend in time series, the whole series can be divided into six segments. Within each segment, linear regression, using time as an independent variable, was applied to explore the linear rule within the sugar price time series, and the results are shown in Table 1.

From the above regression analysis, we conclude that during every increasing and decreasing period, the time series of sugar price reveals a strong linear trend, i.e. the linear relationship between time and sugar price is very strong. In all six segments, the coefficients of determination, namely the R-squared values, are all higher than 0.75 , especially in the fifth segment consisting of the 2009/2010 season, where they climbed as high as approximately 0.93 . Therefore, it can be concluded that in the last 14 years, in every increasing or decreasing trend, sugar price is highly dependent on time and significantly increases/decreases as time passes. Based on the above fact, this paper makes the hypothesis that in a disaster-free scenario the sugar price in the 2009/2010 season is strongly related to time.

month CPI data published by official channels begins from December 2006. On the other hand, CPI in China has begun to increase significantly since 2007. 
Table 1. Results of linear regression analysis of six segments of sugar price over a long period.

\begin{tabular}{lccrcc}
\hline Period & $\begin{array}{c}\text { Number of } \\
\text { observations }\end{array}$ & Intercept & Coefficient & R-squared & $\begin{array}{c}\text { Adjusted } \\
\text { R-squared }\end{array}$ \\
\hline Dec 1999-Apr 2001 & 17 & 2367.04 & $100.30^{*}$ & 0.86 & 0.85 \\
May 2001-Jul 2003 & 27 & 3951.01 & $-78.46^{*}$ & 0.83 & 0.82 \\
Aug 2003-Feb 2006 & 31 & 1950.36 & $64.86^{*}$ & 0.77 & 0.76 \\
Mar 2006-Sep 2008 & 31 & 4755.28 & $-79.74^{*}$ & 0.91 & 0.91 \\
Oct 2008-Dec 2010 & 27 & 2118.31 & $95.72^{*}$ & 0.93 & 0.93 \\
Jan 2011-Dec 2013 & 36 & 5081.84 & $-61.01^{*}$ & 0.93 & 0.93 \\
\hline
\end{tabular}

* significant at $1 \%$ level.

\subsection{Estimation of sugar price in a disaster-free scenario}

When focusing on the time series in the 2009/2010 season, since the squeezing process of the 2008/2009 season ended on 15 April 2009, this date consequently represented the beginning of the 2009/2010 season price trend. 11 September 2010 is taken as the end point of the price trend because by then, the 2009/2010 season had already finished and a new trend, which has little to do with the drought, began on 12 September. To remove the influence of recent rapid development of CPI in China on sugar price, the original time series is then fixed based on April 2009 using month-to-month CPI data (National Bureau of Statistics of the People's Republic of China). Finally, the deflated data set, consisting of $515 \mathrm{ob}-$ servations, is obtained.

In order to obtain sugar price for non-disaster conditions with the help of the pre-disaster sugar price, methods like time series analysis can be applied. Among various advantages of time series analysis, an autoregressive error model is quite effective and frequently used in fields like medicine and health. The main benefit of using it for interruption analysis is that an autoregressive error model can be built when analysing pre-interruption series, and by using this model, series for non-interruption conditions can be predicted. Finally, by comparing actual and predicted series, the effects and dynamics of interruption that occurred can be fully assessed (Yoon et al., 2011; Sills et al., 2011; Kapusta et al., 2007; Ammar et al., 2003). In this paper, the autoregressive error model, expressed as Eq. (1), was applied to fit the predisaster trend. The price series from 15 April 2009 to 22 October 2009 was selected as the pre-disaster sugar price, and the price estimated for the time after 22 October is taken as the sugar price in a non-disaster 2009/2010 season. The results of this model can be seen in table 2 and Fig. 3 .

$\left\{\begin{array}{l}P=C+\beta_{0} t+\mu_{t} \\ \mu_{t}=-\varphi_{1} \mu_{t-1}-\varphi_{2} \mu_{t-2}-\cdots-\varphi_{n} \mu_{t-n}+\varepsilon_{t} \\ \varepsilon_{t} \sim \operatorname{IN}\left(0, \sigma^{2}\right),\end{array}\right.$

where $P$ is the time series of the pre-disaster sugar price, $C$ is a constant and $t$ is time, which is supposed to be 1 on 15 April 2009; it increases by 1 in the days following. $\mu_{t}$ is the
Table 2. Results of autoregressive error model to fit the pre-disaster time series.

\begin{tabular}{lll}
\hline Variables & $\begin{array}{l}\text { Estimated } \\
\text { coefficient }\end{array}$ & $\begin{array}{l}\text { Standard } \\
\text { error }\end{array}$ \\
\hline Constant & $3500^{*}$ & 39.07 \\
$t$ & $2.9108^{*}$ & 0.35 \\
$\mathrm{AR}(1)$ & $1.0524^{*}$ & 0.04 \\
$\mathrm{AR}(4)$ & $-0.1417^{*}$ & 0.04 \\
\hline Total R $\mathrm{R}^{2}=0.98$ & $\mathrm{AIC}=1788.82$ & MAPE $=0.40$ \\
$\mathrm{DW}=2.03$ & $\mathrm{SBC}=1801.62$ & $\mathrm{RMSE}=25.70$ \\
\hline
\end{tabular}

* significant at $1 \%$ level.

error term which follows an autoregressive model of order $n$. The term $\varepsilon_{t}$ is assumed to be normally and independently distributed with mean zero and variance $\sigma^{2}$ (Miller et al., 2004; Moineddin et al., 2003; Chu, 2011).

\subsection{Representative sugar price for disaster-free and disaster-hit scenarios}

To attain sugar prices that can integrate the variation of price and are able to represent the value level of sugar in disaster-hit and disaster-free scenarios, representative sugar prices for both scenarios are estimated. The fact that different amounts of sugar are sold at different prices during the onset of drought has a significant influence on the company's revenue. The estimation of representative sugar prices therefore takes actual selling amounts of sugar into consideration. The amount of sugar sold in Yunnan province for each month of the 2009/2010 season can be abstracted from data from the Yunnan Sugar Network (2014), and then the monthly ratios respective to the total amount sold during the whole season can be calculated, as shown in table 3. Later, the series of daily sugar price is aggregated by means of a simple average to obtain the monthly sugar price, and the ratios above are used as weights for these monthly prices, to create an adjusted sugar price which is able to represent the selling price of the 2009/2010 season, both in disaster conditions and nondisaster conditions. 
Table 3. Amount of sugar sold monthly during the 2009/2010 season.

\begin{tabular}{lrr}
\hline Month & $\begin{array}{r}\text { Monthly sales } \\
(10 \text { 000 tons })\end{array}$ & $\begin{array}{r}\text { Percentage of } \\
\text { whole year }(\%)\end{array}$ \\
\hline December 2009 & 1.96 & 1.23 \\
January 2010 & 13.17 & 8.28 \\
February 2010 & 15.29 & 9.61 \\
March 2010 & 19.72 & 12.40 \\
April 2010 & 19.79 & 12.44 \\
May 2010 & 18.51 & 11.63 \\
June 2010 & 19.04 & 11.97 \\
July 2010 & 23.048 & 14.49 \\
August 2010 & 18.132 & 11.40 \\
September 2010 & 10.41 & 6.55 \\
Total & 159.07 & 100 \\
\hline
\end{tabular}

Source: extracted from the Yunnan Sugar Network.

Using the method above, representative sugar price in the assumed non-disaster condition $P_{\text {sugar-non }}$ is 4651.37 yuan ton $^{-1}$ and representative sugar price in the actual disaster year $P_{\text {sugar-disa }}$ is 4753.21 yuan ton $^{-1}$.

All of the data about the drought event used in this study case are summarized in Table 4.

\section{Economic impacts of drought on the sugar value chain}

\subsection{Analysis of economic impact-forming process}

Using on-the-spot interviews with sugarcane growers and managers working at the Jinke Group in Yuanjiang county, this paper summarizes the profit-forming process in the sugar industry and the effect of disaster upon the process, as shown in Fig. 4. The impact of natural disaster spreads throughout the sugar industry, from sugarcane crop failure, contract fulfilment and farm product processing to the finished product. The impact of drought includes water deficiency for cultivation, quantity and quality decline of sugar production, sugar price in the spot market and, eventually, revenues and profits of both growers and the sugar company.

Grower profit ( $\left.E_{\text {growers }}\right)$ is subject to both income for selling sugarcane $\left(H_{\text {crops }}\right)$ and planting cost $\left(C_{\text {planting }}\right)$. Natural disasters reduce the yield and quality of sugarcane and, ultimately, grower income. However, because planting cost has little to do with drought and because this value remains constant regardless of whether drought occurs, grower profit is mainly determined by income from selling sugarcane.

Procurement cost $\left(C_{\text {procurement }}\right)$, processing cost $\left(C_{\text {processing }}\right)$ and business income $\left(H_{\text {products }}\right)$ determine profits of the sugar company $\left(E_{\mathrm{SC}}\right)$. Sugarcane yield losses directly reduce quantity of raw materials, resulting in a decrease in their sugar output. Degradation of raw material quality caused by disasters also decreases the sugarcane-to- sugar output rate (i.e. the amount of sugar output per unit sugarcane input when producing sugar) and increases the processing cost, thus affecting company profit. A decline in sugar production leads to short supplies, an increase in sugar prices in the spot market $\left(P_{\text {sugar }}\right)$ and thereby an increase in business income. This, in turn, lessens the impact of the disasters on the profit of the sugar company.

Using the framework mentioned above, the revenues and costs for sugarcane growers and the sugar company are obtained for both disaster-free and disaster-hit scenarios. In order to have a comparable evaluation of economic impacts between these two parts, the term "profit loss rate" is applied, which is the ratio of impact on profit (i.e. the difference of profit in disaster-free and disaster-hit conditions) to profit in non-disaster conditions, as a variable to scale and represent the economic impacts of disasters.

\subsection{Profit loss rate models}

Sugarcane grower profit value is jointly controlled by total income and planting cost. The equation to calculate grower profit value $E_{\text {growers }}(d)$ in disaster scenarios is Eq. (2):

$$
\begin{aligned}
E_{\text {growers }}(d) & =H_{\text {crops }}-C_{\text {planting }} \\
& =(1-d) \cdot Q \cdot W \cdot P_{\text {order }}-[(1-d) \cdot Q \cdot W \\
& \left.\cdot M_{\text {planting }}+Q \cdot W \cdot F_{\text {planting }}\right] \\
& =(1-d) \cdot\left(P_{\text {order }}-M_{\text {planting }}\right) \cdot Q \cdot W \\
& -Q \cdot W \cdot F_{\text {planting. }}
\end{aligned}
$$

In this equation, $E_{\text {growers }}$ refers to profit value of sugarcane growers, $H_{\text {crops }}$ refers to their total income, $C_{\text {planting }}$ refers to planting cost and $Q$ refers to disaster-free sugarcane yield; $d$ stands for sugarcane yield reduction rate from drought, which is positively related to disaster intensity; $W$ signifies contract performance rate, $P_{\text {order }}$ refers to the sugarcane purchase price in farming contracts, $M_{\text {planting }}$ refers to the marginal costs of sugarcane planting and $F_{\text {planting }}$ refers to the fixed cost of sugarcane planting. The fixed cost of growers mainly refers to the cost of buying seeds for sugarcane and the cost of transporting seeds to the fields and planting them, and the marginal cost refers to the cost of cultivating and maintaining the life of sugarcane, like using fertilizers. This way of dividing costs is mainly based on the perspective of disasters because the fixed cost is independent from disasters and marginal cost is not.

According to Eq. (2), for any yield reduction rate $d$ from natural disasters, Equation (3) is used to calculate the profit 
Table 4. Background data (2009-2010) of Yuanjiang sugar industry in Yunnan.

\begin{tabular}{|c|c|c|c|}
\hline Items & Data & Items & Data \\
\hline $\begin{array}{l}\text { Sugarcane yield } Q \\
\text { in a disaster-free scenario }\end{array}$ & 654900 tons & $\begin{array}{l}\text { Sugarcane-to-sugar } \\
\text { output rate } R\end{array}$ & $12.88 \%$ \\
\hline $\begin{array}{l}\text { Sugarcane purchase price } \\
\text { in contract } P_{\text {order }}\end{array}$ & 260 yuan ton $^{-1}$ & $\begin{array}{l}\text { Fixed costs of sugar } \\
\text { production, } F_{\text {processing }}\end{array}$ & 20 million yuan \\
\hline $\begin{array}{l}\text { Fixed cost of sugarcane } \\
\text { planting } F_{\text {planting }}\end{array}$ & 137 yuan ton $^{-1}$ & $\begin{array}{l}\text { Marginal costs of sugar } \\
\text { production, } M_{\text {processing }}\end{array}$ & 102.5 yuan ton $^{-1}$ \\
\hline $\begin{array}{l}\text { Marginal costs of sugarcane } \\
\text { planting } M_{\text {planting }}\end{array}$ & 80 yuan ton ${ }^{-1}$ & $\begin{array}{l}\text { Representative sugar price } \\
\text { in a disaster-free scenario, } \\
P_{\text {sugar-non }}\end{array}$ & 4651.37 yuan ton $^{-1}$ \\
\hline $\begin{array}{l}\text { Contract performance } \\
\text { rate } W\end{array}$ & $80 \%$ & $\begin{array}{l}\text { Representative sugar price } \\
\text { in a disaster-hit scenario, } \\
P_{\text {sugar-disa }}\end{array}$ & 4753.21 yuan ton $^{-1}$ \\
\hline $\begin{array}{l}\text { Sugarcane yield } \\
\text { reduction rate } d\end{array}$ & $32.88 \%$ & $\begin{array}{l}\text { Coefficient } k \text { of drought } \\
\text { impact on sugar price }\end{array}$ & 3.10 \\
\hline
\end{tabular}

Sources: 2009 Work Summary Report (Yuanjiang County Sugar Office, 2010), Statistical Communiqué of Yuanjiang autonomous county of Hani, Yi and Dai on the 2009 and 2010 National Economic and Social Development (Bureau of Statistics of Yuanjiang autonomous county of Hani, Yi and Dai, 2010, 2011), authors' on-the-spot investigation.

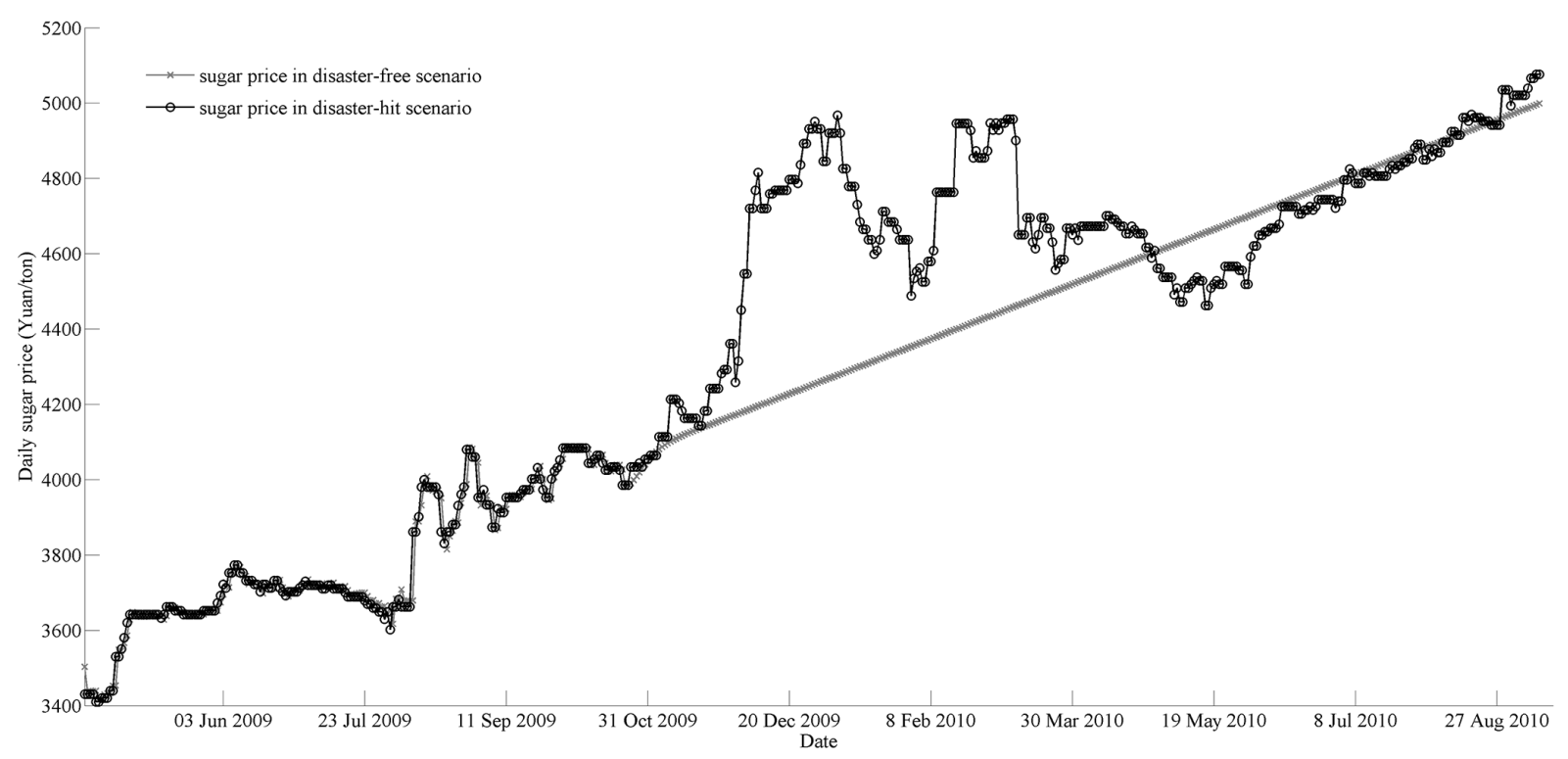

Figure 3. Sugar price in disaster-free and disaster-hit conditions in the 2009/2010 season.

loss rate of growers.

$$
\begin{aligned}
L_{\text {growers }}(d) & =\left(E_{\text {growers }}(0)-E_{\text {growers }}(d)\right) /\left(E_{\text {growers }}(0)\right) \\
& =\left[\left(P_{\text {order }}-M_{\text {planting }}\right) /\left(P_{\text {order }}-M_{\text {planting }}\right.\right. \\
& \left.\left.-F_{\text {planting }}\right)\right] \cdot d \\
& =4.1860 \cdot d
\end{aligned}
$$

Revenue from selling sugar production, sugarcane purchase cost and sugarcane processing costs jointly determine the sugar company's profit. The following equation calculates profit in a disaster year, or $E_{\mathrm{SC}}(d)$.

$$
\begin{aligned}
E_{\mathrm{SC}}\left(d, P_{\text {sugar }}\right)= & H_{\text {products }}-C_{\text {procurement }}-C_{\text {processing }} \\
= & (1-d) \cdot Q \cdot W \cdot R \cdot P_{\text {sugar }}-(1-d) \cdot Q \\
& \cdot W \cdot P_{\text {order }}-[(1-d) \cdot Q \cdot W \\
& \left.\cdot M_{\text {processing }}+F_{\text {processing }}\right] \\
= & (1-d) \cdot Q \cdot W \cdot\left(R \cdot P_{\text {sugar }}-P_{\text {order }}\right. \\
- & \left.M_{\text {processing }}\right)-F_{\text {processing }}
\end{aligned}
$$

In this equation, $E_{\mathrm{SC}}$ refers to profit value of the sugar company, $H_{\text {product }}$ to revenue from selling sugar, $C_{\text {procurement }}$ to raw material procurement cost, $C_{\text {processing }}$ to sugarcane pro- 


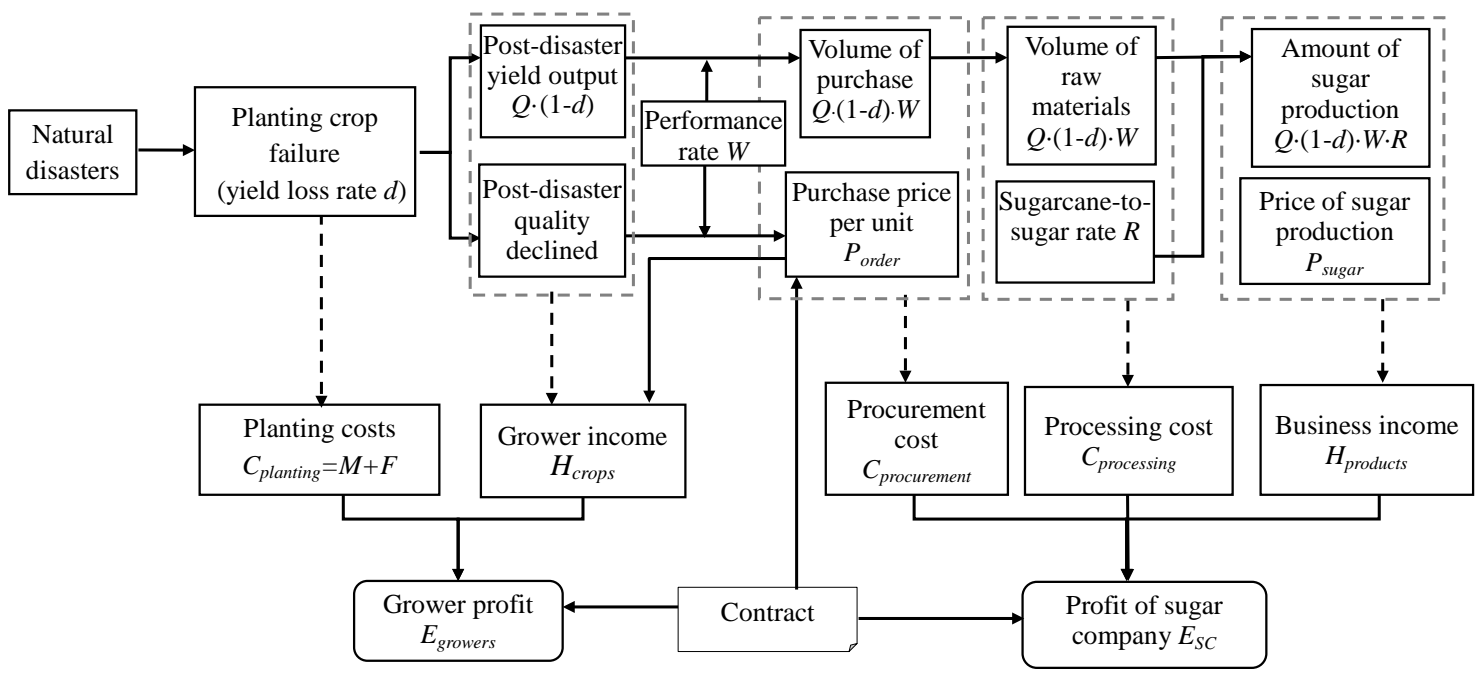

Figure 4. Transfer processes of disasters in the sugar industry.

cessing cost and $Q$ refers to the disaster-free sugarcane yield. $d$ is the sugarcane yield reduction rate caused by drought, $W$ is the contract performance rate, $R$ is the sugarcane-to-sugar output rate, $P_{\text {sugar }}$ is the representative sugar price in either disaster-hit or disaster-free scenarios, $P_{\text {order }}$ is the sugarcane purchase price in the contract, $M_{\text {processing }}$ is the marginal cost of processing sugar and $F_{\text {processing }}$ is the fixed cost for the sugar company to produce sugar. The fixed costs for the sugar company consist of administrative cost, land rent and equipment amortization cost; marginal costs include labour cost, sugar processing cost, wrapping cost and marketing cost.

From Eq. (4), we know that the profit of the sugar company in a disaster year is related to sugar price and yield reduction rate. Therefore, the profit loss rate of the sugar company is shown by Eq. (5).

$$
\begin{aligned}
& L_{\mathrm{SC}}\left(d, P_{\text {sugar }}\right)=\left[E_{\mathrm{SC}}\left(0, P_{\text {sugar-non }}\right)\right. \\
& \left.\quad-E_{\mathrm{SC}}\left(d, P_{\text {sugar-disa }}\right)\right] /\left[E_{\mathrm{SC}}\left(0, P_{\text {sugar-non }}\right)\right]
\end{aligned}
$$

In this equation, $P_{\text {sugar-non }}$ represents sugar price in a disaster-free scenario, and $P_{\text {sugar-disa }}$ represents sugar price in a disaster-hit scenario.

During the period from April 2009 to September 2010, amongst the various influences on sugar prices, the most important cause of price fluctuations is changes in supply because of drought, and other conditions during that period remain similar to those in the pre-disaster period. Consequently, to simplify the analysis, this study assumes a linear variation of sugar price with sugarcane yield to illustrate the impact of drought on sugar price. A linear coefficient $k$ is used to link yield loss and change in representative sugar price. It means that if sugarcane yield decreases by $1 \%$, sugar prices have a linear increase $k$. Hence, $k$ is termed the influence coefficient of a disaster on sugar prices.

In Yuanjiang county, during the 2009/2010 drought, sugarcane yield dropped by $32.88 \%$ and sugar prices increased by 101.84 yuan (calculated from table 4 ). According to the linear relation, for a sugarcane field yield reduction rate of $1 \%$, the sugar price increased 3.10 yuan; that is, the impact coefficient of the drought on sugar prices was $k=3.10$ in Yuanjiang county. Based on these figures, it is hypothesized that sugar price varies linearly with the reduction of sugarcane yields, as shown in Eq. (6).

$P_{\text {sugar-disa }}=100 \cdot k \cdot d+P_{\text {sugar }- \text { non }}$

Here, $k$ is the influence coefficient of disasters on sugar price and $d$ is the sugarcane yield reduction rate caused by drought. From Eq. (4), Eqs. (5) and (6) and applying the $P_{\text {sugar-non }}$ in this case, we conclude that Eq. (7) determines the profit loss rate of the sugar company $L_{\mathrm{SC}}(d)$ :

$$
\begin{aligned}
L_{\mathrm{SC}}(d) & =\left[R \cdot 100 \cdot k \cdot d^{2}-d \cdot\left(R \cdot 100 \cdot k+P_{\text {order }}\right.\right. \\
& \left.\left.+\mathrm{MC}_{\text {processing }}-R \cdot P_{\text {sugar-non }}\right)\right] \quad\left[R \cdot P_{\text {sugar-non }} /\right. \\
& \left.-P_{\text {order }}-M_{\text {processing }}-F_{\text {processing }} /(Q \cdot W)\right] \\
& =0.2012 \cdot d^{2}+0.9912 \cdot d .
\end{aligned}
$$

By taking $d$ from 0 to $100 \%$ for Eqs. (3) and (7), comparison of these two curves of profit loss rate is shown in Fig. 5.

As profit loss rate of growers expressed in Eq. (3) demonstrates, $L_{\text {growers }}(d)$ is related only to sugarcane purchase price fixed in farming contracts and sugarcane-planting costs, and has nothing to do with sugar price. Therefore, profit loss rate of growers does not vary subject to fluctuation in sugar price. Figure 5 shows a linear relationship between yield reduction rate and profit loss rate of growers in disaster-hit year. In the 2009/2010 drought, profit loss rate of sugarcane growers is $137.64 \%$.

For the sugar company, the relationship between the yield reduction rate and the profit loss rate of the sugar company is fitted in a quadratic function as shown in Eq. (7). In the 
$2009 / 2010$ drought, profit loss rate of the sugar company is $34.77 \%$. From Fig. 5, whatever the increase in yield reduction rate, the profit loss rate curve of the sugar company is always below that for growers; that is, for the same disaster severity, the profit loss rate of the sugar company is much less than that of the growers.

Analysis of the root cause of this disparity reveals that it is the sugarcane purchase price subject to the order contract that is the connecting point between upstream growers and the downstream company in the present value chain structure. Sugarcane purchase price has nothing to do with variation of sugar price in such a rigid-order model. Grower income is isolated from the sugar market price because, even if the price rises, their income remains constant.

\subsection{Sensitivity analysis of profit loss rates}

In the research above, by analysing the transfer process of profit loss along the sugar industry chain, it is found that the improper setting of sugarcane purchase price is an important reason that causes unequal sharing of profit loss rate. Also, after analysing the profit loss rate model for both growers and the sugar company, it is found that only sugarcane purchase price $\left(P_{\text {order }}\right)$ may be the significant variable to find out which variable can greatly influence economic impactsharing between growers and the sugar company. This serves the aim of finding solutions for economic inequality in contract farming. Hence, in order to study the sensitivity of sugarcane purchase price, a sensitivity analysis is conducted for this variable. A profit loss rate model, in which sugarcane purchase price is set as an independent variable and other variables are put in as constants, is rebuilt based on former models, as shown in Eqs. (8) and (9).

$$
\begin{aligned}
L_{\text {growers }}\left(P_{\text {order }}\right)= & \left(E_{\text {growers }}(0)-E_{\text {growers }}(d)\right) /\left(E_{\text {growers }}(0)\right) \\
= & {\left[\left(P_{\text {order }}-M_{\text {planting }}\right) /\left(P_{\text {order }}-M_{\text {planting }}\right.\right.} \\
& \left.\left.-F_{\text {planting }}\right)\right] \cdot d \\
= & \left(0.3288 \cdot P_{\text {order }}-26.30\right) /\left(P_{\text {order }}-217\right)
\end{aligned}
$$

$$
\begin{aligned}
L_{\mathrm{SC}}\left(P_{\text {order }}\right)= & {\left[E_{\mathrm{SC}}\left(0, P_{\text {sugar-non }}\right)-E_{\mathrm{SC}}\left(d, P_{\text {sugar-disa }}\right)\right] / } \\
& {\left[E_{\mathrm{SC}}\left(0, P_{\text {sugar-non }}\right)\right] } \\
= & {\left[R \cdot 100 \cdot k \cdot d^{2}-d \cdot\left(R \cdot 100 \cdot k+P_{\text {order }}\right.\right.} \\
& \left.\left.+M_{\text {processing }}-R \cdot P_{\text {sugar-non }}\right)\right] /\left[R \cdot P_{\text {sugar-non }}\right. \\
& \left.-P_{\text {order }}-M_{\text {processing }}-F_{\text {processing }} /(Q \cdot W)\right] \\
= & \left(4.3166+150.1526-0.3288 \cdot P_{\text {order }}\right) / \\
& \left(458.4227-P_{\text {order }}\right)
\end{aligned}
$$

When different values of sugarcane purchase price are applied, profit loss rates for both sugarcane growers and the sugar company can be calculated and the results are shown in Fig. 6. As observed in Fig. 6, when sugarcane purchase price stays at 260 yuan ton $^{-1}$ which occurs in actual practice, the difference of profit loss rates is huge and significant. As sugarcane purchase price rises, profit loss rate for sugarcane growers drops rapidly and that of the sugar company rises slowly. When it reaches about 440 yuan ton ${ }^{-1}$, two curves intersect, which means that profit loss rates for both participators are equal. Furthermore, when sugarcane purchase price rises higher, the profit loss rate for sugarcane growers will be lower than that for the sugar company.

From the sensitivity analysis above, it is established that the profit loss rate model is quite sensitive to the variable of sugarcane purchase price. These findings illustrate that in the practice of contract farming, setting a proper sugarcane purchase price can effectively balance economic impacts on both participators when droughts hit.

\section{Discussion}

To avoid the aforementioned unequal sharing of economic losses caused by rigid contracts, it is suggested that a model of flexible contracts should be promoted. In this flexible model, growers and company fulfil the contract at their agreed normal contract price, except in the case of disaster, when sugarcane purchase price becomes linked to "withdisaster" prices to ensure that they are reasonably sharing the losses caused by disasters. In considering design pricing methods, there are several common aspects that apply in contract farming, like fixed price, flexible price and spot market-related price (Prowse, 2012). Such a flexible pricing mechanism is quite popular in the sugar industry (Eaton and Shepherd, 2001). Also, in the research of Bogetoft and Oleson (2002), it is suggested that using a price schedule will help to create good farming contracts. This concerns issues like purchase price related with spot market price, and also if a minimum price is offered. Using an unfixed pricing mechanism is recommended but the actual form it takes in a local situation needs more consideration.

Furthermore, this work investigates the present "company + growers" contract farming system in China. The value chain analysed in this paper is relatively short, including only growers and the company that processes agricultural products. However, with the development of contract farming in China, this value chain will be lengthened and thereby involve more agents of loss transfer in times of natural disaster. Therefore, the multi-agent contract relationship is a topic for future research.

Limiting by existing data and related materials, among all droughts from 1995 to 2010 in Yuanjiang, only the 2009/2010 drought is quite representative and can be selected as a typical case for analysing economic impact on sugarcane growers and the sugar company. In other droughts, the time ranges of some cases are too long to control the influence of other potential factors on sugar price; some other cases occurred too long ago, for which related time series data, disaster data and background information of the local sugar industry are unavailable; thus models detailed in this paper cannot 


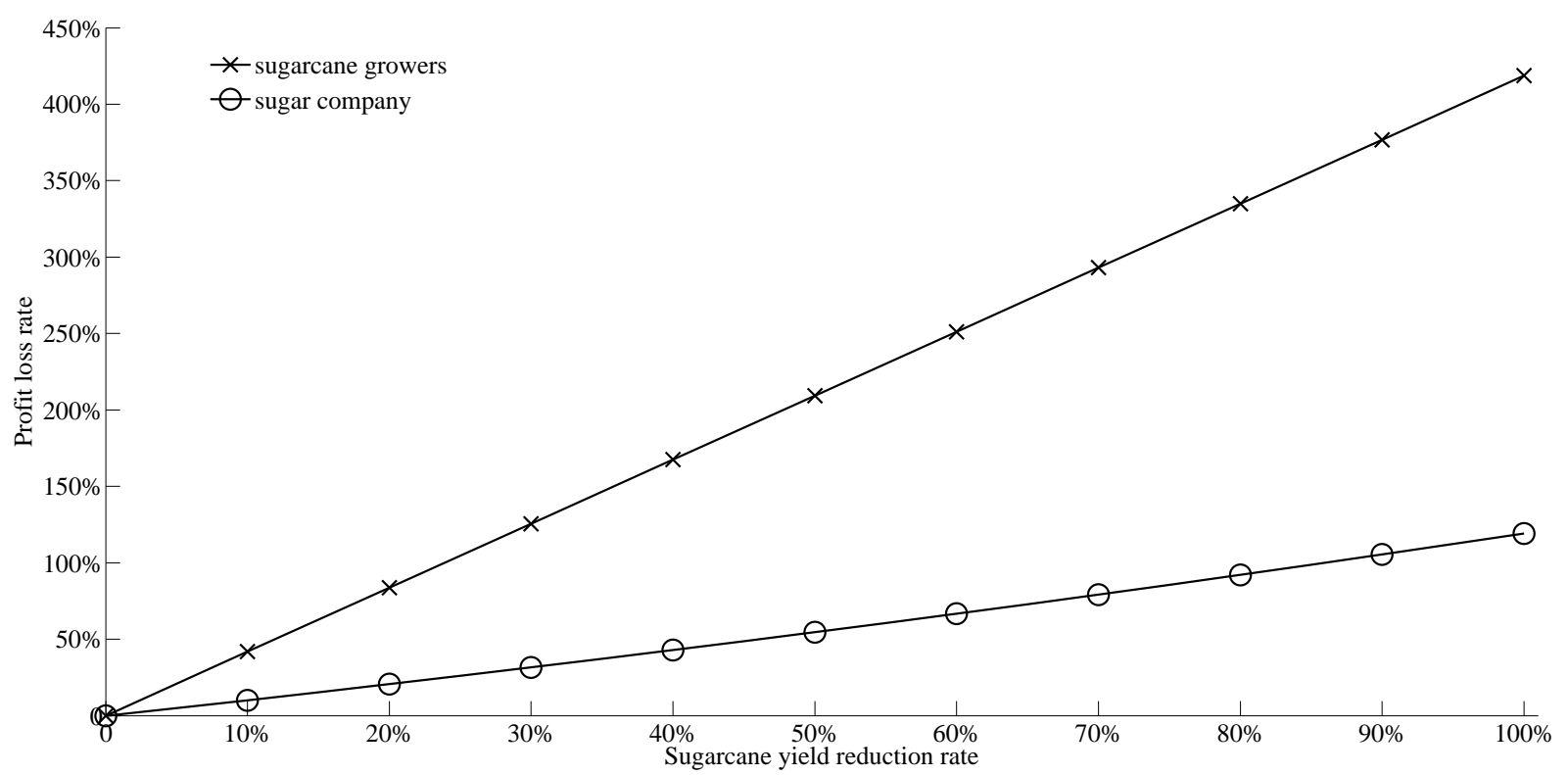

Figure 5. Impact of natural disaster severity on the profit loss rate.

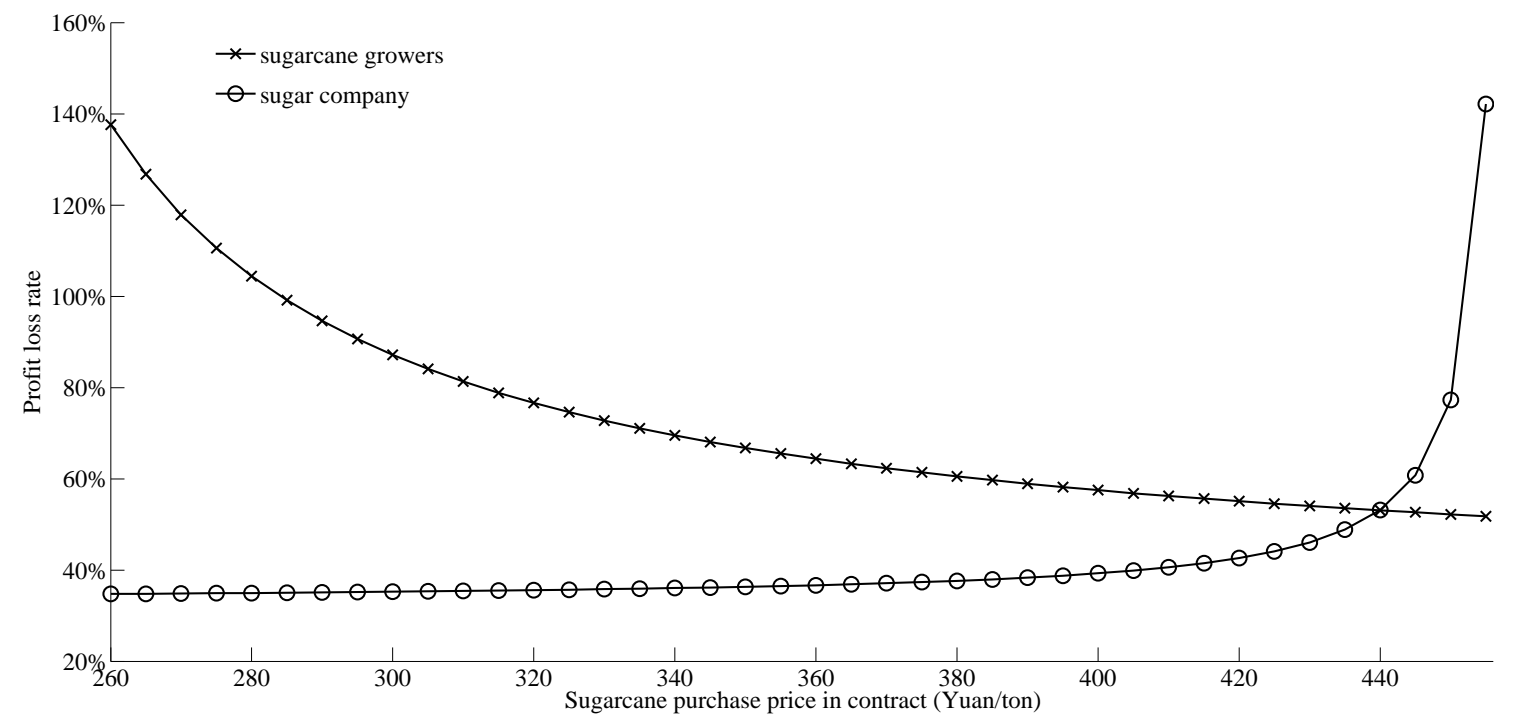

Figure 6. Sensitivity analysis of profit loss rate model.

be applied. In future studies, severe droughts in Yuangjian county will receive more attention and more data and materials related to severe droughts will be accumulated and collected; this will lay down a solid foundation for analysing drought impacts and by using models detailed in this paper, some important coefficients in this model can be examined.

\section{Conclusions}

In this paper, the value chain of the sugar industry involving sugarcane growers and the sugar company is considered in the evaluation of economic impacts of severe drought.
Analysis of "with and without disaster" scenarios lay the foundation of this model and profit loss of growers and the sugar company is generated by comparing the differences in disaster-hit and disaster-free scenarios. Then the profit loss rate is calculated to scale the economic impacts of drought on growers and the sugar company. An endogenous trend in sugar price is identified from a long time series of sugar price and a linear regression model. To estimate the sugar price in a disaster-free scenario, which cannot be observed in the real world, an autoregressive error model, with the support of a pre-disaster price series, is performed to determine the estimated sugar prices in a disaster-free scenario. Taking 
the variation in sugar prices into consideration, representative sugar prices for disaster-free conditions and disaster-hit conditions are integrated from a long time series that covers the whole period of drought.

As a result, the 2009/2010 drought, which occurred in southwestern China, causes the local sugar price to increase by 101.84 yuan ton $^{-1}$. Moreover, the profit loss rates are 34.77 and $137.64 \%$ for the sugar company and growers, respectively. This result means that in the occurrence of severe drought, sugarcane growers in Yuanjiang county face far heavier economic impacts than the local sugar company, which implies that unequal sharing of economic losses in these rigid farming contracts exists during drought.

Furthermore, it is found that once the source of the value chain suffers a natural disaster, losses pass to all principal agents, which thus generate economic losses throughout the value chain in the existing rigid contract farming system. When confronted with a natural disaster, growers suffer more serious losses than the company that produces agrifood. As the severity of disaster strengthens, the profit loss rate of the sugar company remains far less than that of growers. To a large extent, the sugar price that increased with disaster severity compensates for the profit loss of the sugar company. Therefore, within such a rigid contract, economic inequality appears in the face of natural disasters. Flexible farming contracts shall be promoted to make loss-sharing equal.

Sensitivity analysis of the model built reveals that setting a proper sugarcane purchase price will be able to balance economic impacts between growers and the company. Using this sensitivity analysis, a proper sugarcane purchase price can be found and with this price in farming contracts, economic impacts of drought will be fully shared, which introduces an effective method in setting sugarcane purchase price in contract farming.

Through investigating the economic impacts of the 2009/2010 drought, this paper introduces a new framework for assessing the economic impacts of severe drought. The principle of this framework is from the idea of "with and without" analysis (Guimaraes et al., 1993), which indicates that the "loss" in this paper refers to the difference between disaster-hit and disaster-free conditions but not the difference between pre-disaster and pro-disaster conditions, which is otherwise quite popular among published literature. The model developed in this paper is based on a new perspective "profit loss rate" which can reflect net value loss and provide capability for comparing among different individuals. In the details of models built, the generation process of profit for different economic bodies is clearly described and specific features of objects assessed. For example, the internal trend of sugar price and variation of monthly sugar sales are fully considered, which may provide valuable reference for future studies. Moreover, the focus of this research is the transfer dynamics of disaster impacts along the sugar value chain which highlight the sufferings of different individuals in severe droughts. The results of this paper call on disaster evaluation research to pay more attention to microeconomic phenomena and to especially take care of those vulnerable groups like growers in the sugar industry.

Acknowledgements. This work was supported primarily by the National Basic Research Program of China (2012CB955403), National Natural Science Funds (41271544), and the National Key Technology R\&D Program of Twelfth Five Year Plan of China (2012BAK10B03). Several research assistants contributed to this paper, including those at the National Disaster Reduction Centre, Ministry of Civil Affairs and Yuanjiang County Sugar Office.

Edited by: H. Kreibich

\section{References}

Ammar, A., Hanna, A. S., Nordheim, E. V., and Russell, J. S.: Indicator variables model of firm's size-profitability relationship of electrical contractors using financial and economic data, J. Constr. Eng. M. ASCE, 129, 192-197, 2003.

Bogetoft, P. and Olesen, H. B.: Ten rules of thumb in contract design: lessons from Danish agriculture, Eur. Rev. Agric. Econ., 29, 185-204, 2002.

Booker, J. F. and Colby, B. G.: Competing Water Uses in the Southwestern United-States - Valuing Drought Damages, Water Resour. Bull., 31, 877-888, 1995.

Brémond, P., Grelot, F., and Agenais, A.-L.: Review Article: Economic evaluation of flood damage to agriculture - review and analysis of existing methods, Nat. Hazards Earth Syst. Sci., 13, 2493-2512, doi:10.5194/nhess-13-2493-2013, 2013.

Bureau of statistics of Yuanjiang autonomous county of Hani, Yi and Dai: Statistical Communiqué of Yuanjiang autonomous county of Hani, Yi and Dai on the 2009 National Economic and Social Development, available at: http://yxyj.xxgk.yn.gov.cn/Z_M_013/Info_Detail.aspx? DocumentKeyID=1DEDB6F2F98F41868D1C9A9FEEAB0B74 (last access: 30 October 2014), 2010.

Bureau of statistics of Yuanjiang autonomous county of Hani, Yi and Dai: Statistical Communiqué of Yuanjiang autonomous county of Hani, Yi and Dai on the 2010 National Economic and Social Development, available at: http://yxyj.xxgk.yn.gov.cn/Z_M_013/Info_Detail.aspx? DocumentKeyID=1792464697B44DFB8C58A5435E24C911 (last access: 30 October 2014), 2011.

Cashin, P., McDermott, C. J., and Scott, A.: Booms and slumps in world commodity prices, J. Dev. Econ., 69, 277-296, 2002.

Chau, V. N., Cassells, S., and Holland, J.: Economic impact upon agricultural production from extreme flood events in Quang Nam, central Vietnam, Nat. Hazards, 75, 1747-1765, doi:10.1007/s11069-014-1395-x, 2015.

Chu, F. L.: A piecewise linear approach to modeling and forecasting demand for Macau tourism, Tourism Manage., 32, 1414-1420, 2011.

Cuddington, J. T.: Long-run trends in 26 primary commodity prices - a disaggregated look at the Prebisch-Singer hypothesis, J. Dev. Econ., 39, 207-227, 1992. 
Diersen, M. A. and Taylor, G.: Examining economic impact and recovery in South Dakota from the 2002 drought, Department of Economics, South Dakota State University, South Dakota, Economics staff paper 2003-8, 2003.

Eaton, C. and Shepherd, A.: Contract farming: partnerships for growth, FAO Agricultural Services Bulletin, No. 145, 2001.

Finger, R., Gilgen, A. K., Prechsl, U. E., and Buchmann, N.: An economic assessment of drought effects on three grassland systems in Switzerland, Reg. Environ. Change, 13, 365-374, 2013.

Foreign Agricultural Service, USDA: Sugar Annual: China Peoples Republic of, complete text in English available at: http://gain.fas.usda.gov/Recent\%20GAIN\%20Publications/ Sugar\%20Annual_Beijing_China\%20-\%20Peoples\% 20Republic\%20of_2010-4-23.pdf (last access: 05 May 2015), 2010.

Gil, M., Garrido, A., and Hernández-Mora, N.: Direct and indirect economic impacts of drought in the agri-food sector in the Ebro River basin (Spain), Nat. Hazards Earth Syst. Sci., 13, 26792694, doi:10.5194/nhess-13-2679-2013, 2013.

Guimaraes, P., Hefner, F. L., and Woodward, D. P.: Wealth and income effects of natural disasters: An econometric analysis of Hurricane Hugo, The Review of Regional Studies, 23, 97-114, 1993.

Hallegatte, S.: An adaptive regional input-output model and its application to the assessment of the economic cost of Katrina, Risk Anal., 28, 779-799, 2008.

Holt-Giménez, E.: Measuring farmers' agroecological resistance after Hurricane Mitch in Nicaragua: a case study in participatory, sustainable land management impact monitoring, Agr. Ecosyst. Environ., 93, 87-105, 2002.

Horridge, M., Madden, J., and Wittwer, G.: The impact of the 20022003 drought on Australia, J. Policy Model., 27, 285-308, 2005.

Jenkins, K.: Indirect economic losses of drought under future projections of climate change: a case study for Spain, Nat. Hazards, 69, 1967-1986, 2013.

Kahn, M. E.: The death toll from natural disasters: The role of income, geography, and institutions, Rev. Econ. Stat., 87, 271-284, 2005.

Kapusta, N. D., Etzersdorfer, E., Krall, C., and Sonneck, G.: Firearm legislation reform in the European Union: impact on firearm availability, firearm suicide and homicide rates in Austria, Brit. J. Psychiat., 191, 253-257, 2007.

Lindell, M. K. and Prater, C. S.: Assessing community impacts of natural disasters, Nat. Hazards Rev., 4, 176-185, 2003.

Logar, I. and van den Bergh, J. C. J. M.: Methods to assess costs of drought damages and policies for drought mitigation and adaptation: review and recommendations, Water Resour. Manage., 27, 1707-1720, 2013.

Lu, E., Luo, Y., Zhang, R., Wu, Q., and Liu, L.: Regional atmospheric anomalies responsible for the 2009-2010 severe drought in China, J. Geophys. Res., 116, D21114, doi:10.1029/2011JD015706, 2011.

Martin-Ortega, J., González-Eguino, M., and Markandya, A.: The costs of drought: the 2007/2008 case of Barcelona, Water Policy, 14, 539-560, 2012.

Meyer, V., Becker, N., Markantonis, V., Schwarze, R., van den Bergh, J. C. J. M., Bouwer, L. M., Bubeck, P., Ciavola, P., Genovese, E., Green, C., Hallegatte, S., Kreibich, H., Lequeux, Q., Logar, I., Papyrakis, E., Pfurtscheller, C., Poussin, J., Przy- luski, V., Thieken, A. H., and Viavattene, C.: Review article: Assessing the costs of natural hazards - state of the art and knowledge gaps, Nat. Hazards Earth Syst. Sci., 13, 1351-1373, doi:10.5194/nhess-13-1351-2013, 2013.

Miller, B., Kassenborg, H., Dunsmuir, W., Griffith, J., Hadidi, M., Nordin, D. D., and Danila, R.: Syndromic surveillance for influenzaelike illness in an ambulatory care network, Emerg. Infect. Dis., 10, 1806-1811, 2004.

Ministry of commerce, P. R. China: Announcement No. 74, 2008 of Ministry of Commerce, Promulgating Detailed Rules for Application and Distribution of Import Tariff Quotas of Sugar in 2009, brief version in English available at: http://english.mofcom.gov.cn/article/policyrelease/ domesticpolicy/200810/20081005815768.shtml (last access: 05 May 2015), complete version in Chinese available at: http://www.mofcom.gov.cn/aarticle/b/c/200809/ 20080905807762.html (last access: 05 May 2015), 2008.

Moineddin, R., Upshur, R. E., Crighton, E., and Mamdani, M.: Autoregression as a means of assessing the strength of seasonality in a time series, Popul. Health Metr., 1, 10, doi:10.1186/14787954-1-10, 2003.

National Bureau of Statistics of the People's Republic of China: Archive of month-to-month Consumer Price Index from 2006 to 2010, available at: http://data.stats.gov.cn/workspace/index ?m= hgyd (last access: 30 October 2014), 2014.

Pauw, K., Thurlow, J., Bachu, M., and Van Seventer, D. E.: The economic costs of extreme weather events: a hydrometeorological CGE analysis for Malawi, Environ. Dev. Econ., 16, 177-198, 2011.

Pelling, M. and Uitto, J. I.: Small island developing states: natural disaster vulnerability and global change, Global Environmental Change Part B: Environmental Hazards, 3, 49-62, 2001.

Prowse, M.: Contract farming in developing countries: a review, Agence Française de Développement A Savoir No. 12, 2012.

Sills, M. R., Hall, M., Simon, H. K., Fieldston, E. S., Walter, N., Levin, J. E., Brogan, T. V., Hain, P. D., Goodman, D. M., FritchLevens, D. D., Fagbuyi, D. B., Mundorff, M. B., Libby, A. M., Anderson, H. O., Padula, W. V., and Shah, S. S.: Resource Burden at Children's Hospitals Experiencing Surge Volumes During the Spring 2009 H1N1 Influenza Pandemic, Acad. Emerg. Med., 18, 158-166, 2011.

Toya, H. and Skidmore, M.: Economic development and the impacts of natural disasters, Econ. Lett., 94, 20-25, 2007.

West, C. T. and Lenze, D. G.: Modeling the Regional Impact of Natural Disaster and Recovery - a General Framework and an Application to Hurricane-Andrew, Int. Reg. Sci. Rev., 17, 121150, 1994.

Xie, W., Li, N., Wu, J.-D., and Liu, X.-Q.: Evaluation of indirect loss from hypothetical catastrophes in two regions with different economic development levels in China, Nat. Hazards Earth Syst. Sci., 12, 3325-3335, doi:10.5194/nhess-12-3325-2012, 2012.

Xinhua Net: The total sugar production of China in Season 2009/2010 is about 11 million tons, complete version in Chinese available at: http://news.xinhuanet.com/fortune/2010-03/ 03/content_13087528.htm (last access: 05 May 2015), 2010.

Yang, J., Gong, D., Wang, W., Hu, M., and Mao, R.: Extreme drought event of 2009/2010 over southwestern China, Meteorol. Atmos. Phys., 115, 173-184, doi:10.1007/s00703-011-01726, 2012. 
Yoon, Y. K., Lee, S. E., Lee, J., Kim, H. J., Kim, J. Y., Park, D. W., Sohn, J. W., and Kim, M. J.: Risk factors for prolonged carriage of vancomycin-resistant Enterococcus faecium among patients in intensive care units: a case-control study, J. Antimicrob. Chemoth., 66, 1831-1838, 2011.

Yuan, Y. F.: Impact of intensity and loss assessment following the great Wenchuan Earthquake, Earthq. Eng. Eng. Vib., 7, 247-254, 2008.

Yuanjiang County Sugar Office: 2009 Work Summary Report, unpublished, 2010.
Yunnan Sugar Network: China imports more than 1 million tons of sugar in 2009, complete version in Chinese available at: http:// www.ynsugar.com/Article/ZXZX/JCK/201002/21220.html (last access: 05 May 2015), 2010.

Yunnan Sugar Network: Kunming White Sugar Spot Price, available at: http://www.ynsugar.com/spotprice/sugarchart_km.html, last access: 30 October 2014. 